\title{
SHARED KNOWLEDGE AND UNDERSTANDINGS IN ORGANIZATIONS - ITS DEVELOPMENT AND IMPACT IN ORGANIZATIONAL LEARNING PROCESSES
}

\author{
KLAUS-PETER SCHULZ* \\ Chemnitz University o Technology
}

\begin{abstract}
In the following paper, I will consider the role of collectively shared background assumptions on development processes in organizations. The theoretical concept of the paper is based on a merger of background assumptions models with those of learning and development. The paper is based on the basic view that the fusion of theories should recognize coherence concerning their paradigmatic background. Hence, I will refer to theories that can be assigned a practice theoretic paradigm. The models "theory in use" by Argyris and Schön and "local theory" by Baitsch assume that background assumptions are tacit and collectively shared. They significantly influence activity within organizations. Therefore, a change in background assumptions can be seen as main requisite for organizational development. The process of development can be described with the model of "expansive learning" by Engeström, who explains how collective development emerges in social systems. The effects of change of background assumptions and expansive learning are discussed on the basis of an empirical survey. It describes the creation of background assumptions and the discursive process when different understandings are confronted with each other. Results of this discursive process can be seen as a major aspect in whether change and development can take place at an organizational level or not.
\end{abstract}

\section{INTRODUCTION}

Within the debate of organizational learning a considerable faction emphasizes actors and their activity as a central analytical perspective. Such actor and activity theoretic views consider organizational learning as a consequence of individual and collective development processes (e.g. Virkunnen and Kuuti 2000; Engeström 2001). However, what factors trigger and influence such development processes? Engeström, in his concept of "expansive learning" (1987; 2001) identifies contradictions of individuals in social systems as driving factors. Following Engeström and Bateson (1972) contradictions occur when individuals or groups are unable to solve problems on the basis of their existing knowledge, experience and understandings. Hence the change of these background assumptions can be seen as a prerequisite for individual and collective development. Although the above authors conceptualize development on the basis of changed background assumptions they leave a gap when asking more thoroughly about the characteristics, scope or allocation of those understandings, experience, knowledge and values shared in organizations by its members.

\footnotetext{
* Klaus-Peter Schulz, Chemnitz University of Technology, Department for Innovation Research and Sustainable Ressource Management, BWL IX, 09107 Chemnitz, Germany, Tel.: ++49 371 531 35234, Fax.: ++49371 531 835234, Email: schulzkp@wirtschaft.tu-chemnitz.de
} 


\section{Proceedings of OLKC 2007 - “Learning Fusion”}

These aspects have been discussed in two other concepts of organizational learning: "local theories" by Elden (1983) and later Baitsch $(1993 ; 1996)$, and "theories-in-use" by Argyris and Schön (e.g. 1978; 1996). These authors regard background knowledge, experience and understandings as collectively shared within communities. Further, individuals and groups are themselves not aware of them. Nevertheless they significantly influence behavior in organizations (Baitsch 1993).

Therefore, I see the contribution of this paper by merging the activity theoretic concept of "expansive learning" by Engeström with the two analytical models of background assumptions from Argyris and Schön, and from Elden and Baitsch. These theories can be assigned an actor-centred and activity-oriented view. Hence the models refer to comparable basic scientific assumptions. The paper will focus the collective and organizational aspect of background assumptions and its impact on organizational development. It is structured as follows and contains the subsequent aspects:

- A preliminary view on the merger of perspectives and theories.

- A theoretic description about the above concepts of background assumptions and the theory of expansive learning; including discussion of their current state in research since the basic models date from the 1980s and 1990s.

- Discussing the question where collectively shared background assumptions can be allocated in organizations, be it formal structures or informal relations. The metaphor of communities of practice (e.g. Swan et. al. 2002; Wenger 2003) may provide a useful concept here.

- A qualitative empirical study provides information about the creation of background assumptions and the discursive process when different understandings are confronted with each other (Schulz 2005; 2006). Results of this discursive process can be seen as a major aspect in reference to whether organizational change and development can take place or not.

\section{MERGING THEORIES - GENERAL THOUGHTS}

Considering research approaches that merge theories, it may be distinguished between two general scientific strategies. In the first one, the research object is considered from different perspectives and disciplinary angles. Such strategy should go ahead a clarification about the different meanings of concepts and expressions. Standpoints can however be contradictive. In such case the dichotomy between the perspectives makes it difficult to merge the positions since the scientific basis contains opposing views. This fact is not only related to content and the meaning of terms, but also to methodological questions. Not only do the objects of analysis themselves differ, but also the way in which they can be investigated. The scientific contribution of comparing theories grounded in different views can be separation and distinction of standpoints or the expansion of views. To benefit from different views, arguments should be evaluated in light of the basic assumptions they contain. Therefore, researchers have to become aware of their own scientific basis. As a consequence, the conflict between different theories being combined in an eclectic manner, or between different positions being dismissed as heretical because they do not fit into a scientific framework, can be avoided. The different approaches to learning in cognition theory, behavior science or social theories can be seen as an example of different basic views that can be discussed but hardly be merged. 
Therefore, my suggestion for merging theories is the second strategy - to allocate theoretic positions to their scientific basis, their paradigm, and to merge theories that reference the same paradigm. This approach is based on the view that human thinking and cognition are characterized through background knowledge and assumptions (Fleck 1935). Within scientific communities, these assumptions are normally perceived as theories. Thomas Kuhn states that the coherence of scientific communities cannot be explained by the existence of shared theories (1962). According to Kuhn, theories themselves are also based on background assumptions which he calls paradigms (1962: 26, 194). Coherence of scientific groups results from the (implicit) share of a paradigm. Hence, scientific communities are themselves not necessarily aware of its background. Benefits, however, lie in an explicit reference to a specific paradigm, since it can provide a consistent argumentation either content or methodology related. This approach is not only relevant as methodology of this paper, but the meaning of background assumptions in organizational work life will be discussed in the following. The contribution of a paradigmatic based merger of theories can be seen in considering additional facets of research issues and therefore facilitate a more comprehensive picture of the research object than one single theory could do.

The paradigm referred to in this paper can be subsumed as "theories of practice" which includes schools or grounded theories such as pragmatism (e.g. Dewey; 1938/1988; Argyris and Schön 1978), activity theory (e.g. Vygotskij 1978; Engeström 1987) or praxéology (e.g. Bourdieu 1990). These concepts consider practice as object of research in its specific situation and context. Hence, research has to cope with complexity and peculiarity of the context. However, apart from subjectivist approaches theories of practice do not remain in the setting of the specific situation but develop general mechanism and models out of practice. Therefore, theories of practice can be seen as dialectics between the reification of practice and the appropriation of theory (Schulz and Aderhold 2004).

\section{THEORETIC VIEW ON BACKGROUND ASSUMPTIONS AND EXPANSIVE LEARNING}

\subsection{Background Assumptions and Theory Building}

Social theories of learning that refer to a paradigm of "theories of practice" can be seen as analytical models that address how individuals become practitioners in new contexts through growing into that new practice (e.g. Lave/Wenger 1991; Brown/Duguid 1991; 2001). Considering work processes, the novice who enters a new community is rarely free of pre-experience from other contexts (except the traditional apprenticeship model). Generally, newcomers have either worked in similar industries or performed comparable jobs. Therefore, "growing into a new context" results in a "growing together". Ideally an exchange of experience between experts is brought about in work communities (e.g. Orr 1996). Nevertheless, newcomers have to cope with existing structures, rules and power relations in their new work environment. Parts of them are explicated in user manuals or organization handbooks. They are easy to adopt. Organizational reality is, however, far more influenced by informal rules and cooperation relations that are hardly accessible from outside. The newcomer may come to understand how the "new" organization works through the access of personal experience. Access can only be provided through the other members of the work community - what Lave and Wenger call legitimization (1991); 


\section{Proceedings of OLKC 2007 - "Learning Fusion”}

experience is achieved through practicing within the context. Although the apprenticeship relation, which is stated in several situated learning theories (e.g. John-Steiner 1985; Rogoff 1990; Lave and Wenger 1991), can hardly be assumed in modern work processes. The more experienced a newcomer is, the more challenging he or she may find the confrontation with the new situation compared to his or her former one. This is, however, not a one way process. Especially newcomers that enter outstanding positions, challenge the views and behavior of established members of the organization.

These views that significantly influence behavior can be defined as background knowledge, experience and understandings of an individual, brought about through practicing. An individual within a social system gathers experience through activity, develops ideas about their own work and the surrounding social system. Furthermore, the individual adopts the ways of acting, convictions and values of the community where he or she participates. These characteristics represent the historical development of the social system in its environment. In general, the individual is not aware of these background assumptions, although they characterize activity within a community. Argyris and Schön define such background assumptions as "theories in use" (e.g. 1974: 6ff; Argyris et al. 1985: 81ff). Theories in use are brought about by means of cooperation and communication. Since theories in use result from activity, learning and development in social practice, they are shaped through the convictions of the community the individual is a member of. Hence, the background assumptions of an individual represent the collective background of his or her cooperation partners. Argyris and Schön define "theory in use" as a theory of action (ibid). They focus on the aspects of what drives actions within a social community. Hence, theories in use can be related to the expressions of tacit knowledge and knowing (e.g. Polanyi 1966; see also Schön 1987: 25). The organizational psychologist Christof Baitsch follows a similar approach. However, he focuses on what drives social systems in general. His approach to background assumptions is more related to general views, understandings, convictions and values. Corresponding to the action researcher Max Elden, Baitsch defines such background as "local theory" (Baitsch 1993; 1996; see also Elden 1981; 1983). The term "local" expresses that background assumptions relate to a specific context. Furthermore, in contrast to Argyris and Schön, whose "theory in use" can be seen as a mainly individual concept of action, Baitsch stresses the collective aspect of background assumptions: local theories are collectively shared within a working group (Baitsch 1993: 25ff). The expression "working group" in Baitsch's sense comes very close to the concept of communities of practice (e.g. Lave and Wenger 1991; Swan et al. 2002). Hence, local theory refers rather to real cooperation relations then to formal groups (ibid.). The expression "collectively shared" can be interpreted that there is an overlap of understandings and convictions between members of a group but also a distinction. The latter aspect results from the fact that individuals participate at different communities in parallel.

Following the authors, "local theory" and "theory in use" are of tacit character. Hence, individuals are not aware of these background assumptions and therefore are not easily accessible. Comparing the more action oriented concept of theory in use with the more value and social system oriented local theory in terms of lifecycle and stability a significant difference can be identified: Theories in use may change on the short run through development in work conditions or change of actions or products. Local theories, however, can be seen as being far reaching while resisting rapid change. Shared values, understandings and convictions hold together communities and can also distinguish from 


\section{Proceedings of OLKC 2007 - “Learning Fusion”}

other communities (this is also valid for the cohesion and distinction of the scientific communities mentioned above; see Kuhn 1962).

Although background assumptions are tacit, informal and members of communities are not aware of them, their effects can be identified in the way people behave or in the development of specific tools and instruments (see also Bourdieu 1990: 52ff.). Baitsch describes these explications of local theory as "materialization" (1993: 24). The organizational development of firm set-ups can be seen as an example of the materialization of local theory. In the first stage, cooperation relations are often informal without manifested procedures. With ongoing practice the ways of acting and general understandings are fixed in visions and manuals. Materializations also leave their mark in local theories: People interpret formalities and make use of them in daily work. Therefore formal rules are unconsciously applied in work practice. Hence, the relation between background assumptions and explicit formalities can be seen as dialectics between appropriation and reification (Schulz 2006: 71).

Argyris and Schön consider this explanatory knowledge as "espoused theory" (e.g. 1978). In contrast to theories in use, espoused theories are explicit and generally accessible. An individual is aware of such theories when using them. Espoused theories can be developed out of practice or its background assumptions through reflection on action. On the other hand, espoused theories become part of theories in use through rule based and reflected practicing. However, one should be aware that theories in use and espoused theories are only partially transferable. This aspect stands in contrast to some knowledge management models (e.g. Nonaka and Takeuchi 1994). The relation between local theory and its materialization follows a similar principle, should however be considered as being more complex, since local theory is shared within a whole community and values, and convictions are emotional aspects. Hence, materializations of local theory should not be seen as its explicit reproduction but as expression of a specific style of thinking (see also Fleck 1935).

Although these concepts have their origins in concepts developed in the 1970s and 1980s, concepts of organizational learning and management research often refer to the above theories of background assumptions. Some more recent concepts have adopted the ideas of shared and tacit backgrounds of communities, such as local ontologies (e.g. Gergen 1999: 81). Local theory, however, is more or less restricted to German language area since Elden applied the model only in action research and Baitsch hardly published about in English language. Especially social constructivist workplace learning models or management concepts refer to the concept of local theory (e.g. Scholz 2002; Rüegg-Stürm 2003).

The characteristics of background assumptions can be summarized as follows (see figure 1):

- Background assumptions are the driving force of operational practice; however, they may be distinguished in action related theories-in use and more general and stable values and convictions - local theory.

- Local theories are collectively shared within communities; people are normally not aware of them.

- The relation between background assumptions and explicit theories, instruments, knowledge can be seen as a dialectic one. Especially local theories, including far 
reaching values and convictions, express only indirectly in specific behavior and formal manifestations.

\begin{tabular}{|c|c|c|c|}
\hline \multicolumn{2}{|c|}{ Background assumptions } & & \multirow{2}{*}{$\begin{array}{l}\text { Espoused theory I } \\
\text { materialization }\end{array}$} \\
\hline \multirow[t]{2}{*}{ Local theory (Baitsch) } & \multirow{2}{*}{$\begin{array}{l}\text { Theory in use } \\
\text { (Argyris/Schön) }\end{array}$} & \multirow{7}{*}{$\begin{array}{l}\text { partial } \\
\text { explication } \\
\text { through } \\
\text { reflection }\end{array}$} & \\
\hline & & & - explanation of action \\
\hline $\begin{array}{l}\text { - values, } \\
\text { - general understandings } \\
\text { - convictions }\end{array}$ & $\begin{array}{l}\text { - tacit knowledge } \\
\text { - experiences }\end{array}$ & & $\begin{array}{l}\text { - every day theories } \\
\text { - scientific knowledge }\end{array}$ \\
\hline $\begin{array}{l}\text { developed through long term } \\
\text { enculturation processes }\end{array}$ & $\begin{array}{l}\text { developed through experience } \\
\text { and intuition }\end{array}$ & & $\begin{array}{l}\text { - generated/changed } \\
\text { through analyses of actions } \\
\text { and theory-in-use }\end{array}$ \\
\hline \multirow{3}{*}{$\begin{array}{l}\text { - high stability } \\
\text { - far reaching } \\
\text { - responsible for cohesion } \\
\text { and distinction of com- } \\
\text { munities }\end{array}$} & \multirow{3}{*}{$\begin{array}{l}\text { - stable but changeable } \\
\text { through changed work } \\
\text { conditions }\end{array}$} & & \\
\hline & & & $\begin{array}{l}\text { - stable but dependant on } \\
\text { background assumptions }\end{array}$ \\
\hline & & & \\
\hline \multicolumn{2}{|c|}{ tacit, unconscious, in-transparent, context related } & & $\begin{array}{l}\text { explicit, aware, transparent, } \\
\text { abstract, generally }\end{array}$ \\
\hline
\end{tabular}

\section{Figure 1: The relation between background assumptions and explicit theories}

\subsection{Expansive Learning}

Background assumptions in terms of tacit knowledge and experiences (theories in use) as well as general understandings, values, convictions (local theory) influence activity and behavior within communities and therefore of organizations. Especially individual and organizational learning are influenced by the collectively shared background of its members. The above theories however leave the aspect open, what effects the change of background assumptions has on learning in organizations.

Engeström focused on this aspect when developing the concept of "expansive learning" (1987). According to Bateson (1972) Engeström distinguishes between three levels of learning. The first one is a simple reproduction and optimization of existing practice; the second one includes the methodological aspect "learning how to learn". Ad-hoc and reflected problem solving in work processes can be related to such learning levels. Although level two includes a complex examination of the situation and the adoption of experiences from other contexts, general assumptions and understandings are not questioned. At the third level, learning level however, problems can not be solved on the basis of the existing background of an individual or community. Contradictions between experiences, values, understandings, and possible problem solving occur. Bateson defines this situation as "double-bind" (1972). Triggers for such double bind can be unexpected problems that occur in work processes, new framework conditions or newcomers that join an existing community of practice. These causes are characterized through the confrontation of an existing community with facts that challenge its valid understandings and convictions (Engeström 1987; 2001). Following Engeström, individuals or communities can only overcome this double-bind situation through questioning its background assumptions and redefining their understanding of work. 


\section{Proceedings of OLKC 2007 - “Learning Fusion”}

The cycle of expansive development can be described as follows (Engeström 1987: 189; 2001: 152): (1) A primary contradiction emerges through problems or interventions in the existing community that question existing practice. (2) Analysis of the situation leads to the result that the primary contradiction cannot be solved on the basis of existing understandings and knowledge. A double bind situation occurs. (3) Activity within the community has to be redefined on the basis of a changed understanding. (4) The new model of activity has to be implemented which may cause additional contradictions, since it shows whether the theoretic assumptions taken in step three bear close examination in work practice. (5) Change of work practice can not be seen as a singular action of one individual or group. Therefore a further contradiction is likely to occur when the new practice will be established within an organization. Engeström considers this cycle of expansive learning as process of individual and collective development (ibid.) - in other words: change of background assumptions followed by the change of practice is a prerequisite of development in organizations. The single steps, however, have not to be followed successive. Recursive loops may occur to preceding ones. Further, since change of background assumptions and the development of new work practice is a far reaching act in organizational reality it is likely that this process fails due to power relations and resistance of persons affected.

The basic concept of expansive learning dates from 1987, explaining development of a subject which is embedded in a social system. The actor in Engeström's concept of expansive learning can either be an individual or several persons, who are embedded in a social community. His characteristics of the social community, which he terms an activity system (ibid.), include the reference to actual and informal cooperation relations. Therefore, Engeströms unit of analysis can rather related to the model of communities of practice then to group conceptions. Expansive learning therefore is defined as being collective, however effects on the analytical level "organization" has not been defined. In newer publications, the concept of expansive learning has been developed towards an organizational learning model (Engeström 2001; see also Virrkunen and Kuutti 2000; Kerosuo 2006). Hence, expansive learning can be seen as model for the development of interacting communities and its effects to formal organizations such as firms.

\subsection{Merging Theories of Background Assumptions with the Concept of Expansive Learning}

Although Engeström (and Bateson) considers the change of background assumptions a central aspect in his concept of expansive learning, his exposition lacks a detailed description of its background assumptions'and characteristics. This gap can be closed with the models of local theory and theories in use. The above authors can be related to a theory of practice paradigm. Hence, they all consider individuals within social reality. Further, the revised works of Engeström and the local theory concept from Baitsch both refer to a social system representing real cooperation relations comparable to communities of practice. In both conceptions these communities stand in interrelations with other surrounding communities.

Considering again the cycle of expansive development, Engeström defines the change of background assumptions to find a solution for the double bind as the third step in this process. Since in the following steps work activity is redefined, the change of background assumptions can be interpreted as being something fundamental. Hence, it can be defined 
as a change in local theory - in values, convictions and basic understandings. Although since local theory is, in the interpretation of Baitsch, tacit and collectively shared within a community its aware and ad-hoc change requires its (partial) explication and analysis through collective reflection and discussion. One should be aware that an explication of local theories only represents an incomplete picture, since its contents can only be partially described. This process shows an internal hierarchy between the different types of background assumptions. Local theories which are more related to the general terms work and practice are subject to change to overcome the double binds. Theories in use, which refer to actions, may be developed further in the following steps of the expansion cycle; when new activity is put in concrete forms. The realization of new work and cooperation relations as the last step of the expansion cycle can be seen as appropriation of the changed local theory in work practice. In this step espoused theories are developed to manifest new instruments, rules and work structures.

\section{CASE STUDY}

In the case study a model for learning and development in the pharmaceutical industry is described. The learning concept with its central element, an interactive process simulation taking place in real production environment, has already been described (e.g. Schulz 2005). Performance of the learning program has been investigated in a qualitative empirical study using participatory observation and semi structured interviews (Schulz 2006). In this paper the empirical findings have been analyzed in terms of change of background assumptions of participants and expansive development of communities and work.

\subsection{Case Description}

In the late 1990s and the beginning of the current decade, a global Swiss-based pharmaceutical company had to cope with significant change through its merger with another pharmaceutical producer, new product lines and considerable growth. Especially in terms of production and logistics, people have been confronted with transformation processes. To manage these effects and to provide prerequisites for further change a staff qualification program was developed and has been in operation since 2001. The program focussed on two goals, first to generate a corporate understanding of the process chain and second to create prerequisites to develop operational practice further.

The process simulation which is called the "Process Rally" takes place in the original working context. Participants are approximately 10 to 12 people, originally working in different processes of the process chain or in support functions. This group of participants plans manufactures and checks an original for-sale product within two days (figure 2). The participants have to execute necessary activities at the original working places (offices, laboratories and workshops), using original devices such as protocol-papers and tools. Some actions are entirely identical with operational work; others are simulated due to time limitations or specific detailed knowledge required. Some actions are carried out manually due to didactic reasons such as computer processed planning procedures. The simulation is supported by program leaders who guide the group through. They explain the general methodology and introduce each process step. Since more or less each participant represents one production step he or she can be seen as the expert in carrying out this step. He or she should guide his or her colleagues through these activities. However, the expert role changes from process step to process step. Hence, activity can be described as a 


\section{Proceedings of OLKC 2007 - "Learning Fusion”}

permanent changing learning - teaching relation. However, due to the complexity of activities, and the voluntary nature of the expert role, a further support for participants is needed. Thus, at each process step there exists a process advisor who originally works there and who gives additional support and guidance if needed.

The Process Rally takes place approximately every 6 weeks with different participants. Since 2001 around 50 Rallies have been performed with a total of 520 participants. Apart from practicing, reflection plays an important role during the process simulation. There exist various triggers for reflection such as personal experience, instructions or discussions. It is a type of reflection-on-action (Schön 1987). Thus, topics of reflection are the operational practices of the participants. They likely relate experiences from the process simulation to their operational work. The process simulation should not be seen as a single training program, furthermore it has to be related to the operational practices of participants. However, this is not a question of knowledge transfer but of the relation between operational practice and reflection through the simulation. This relation can be seen as being essential for individual and collective learning and subsequently for the development in organizations.

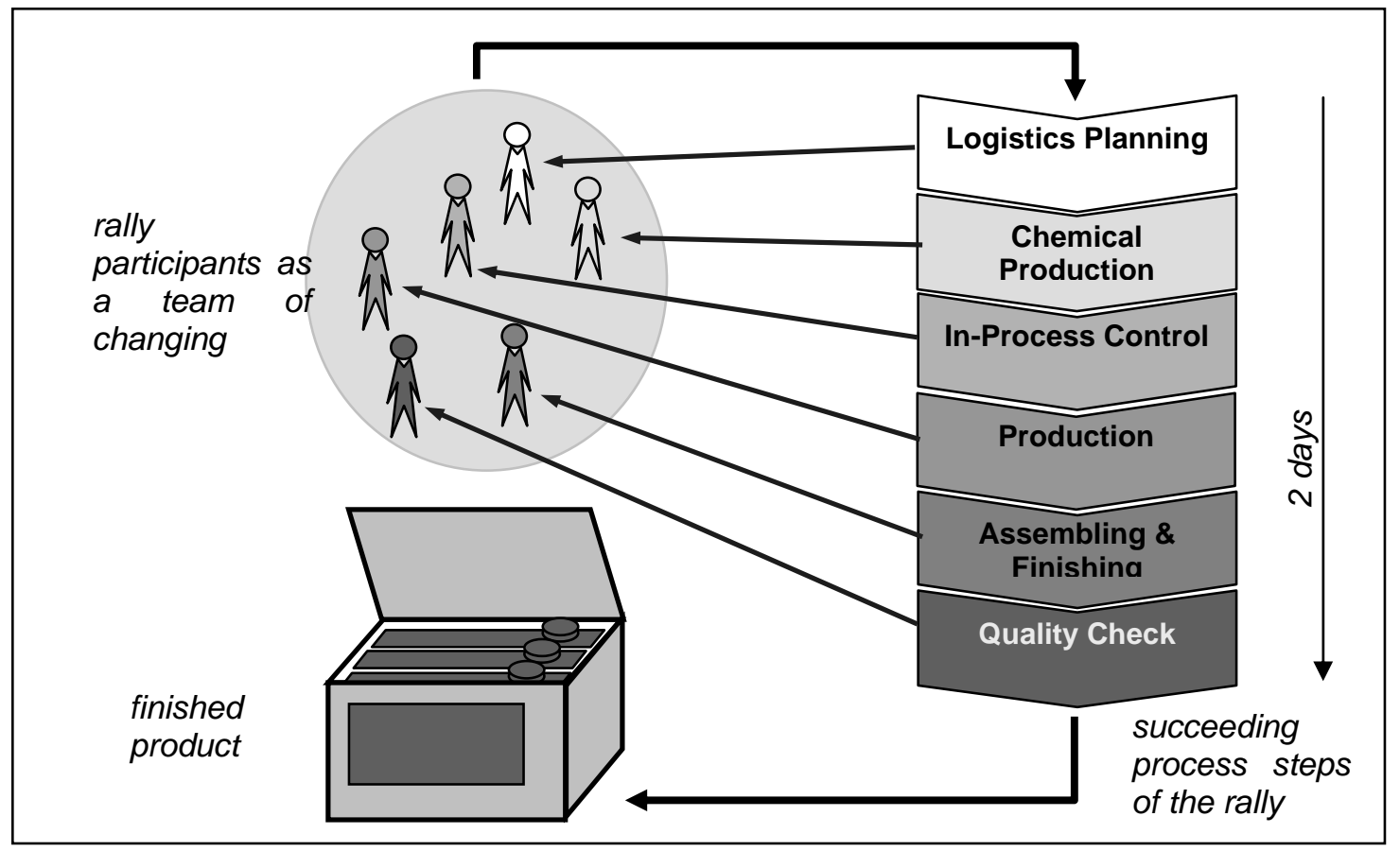

Figure 2: The concept of the Process Rally

\subsection{Methodology}

The empirical survey is based on qualitative methods of social research, to gain an in-depth insight of effects. Since local theories or expansive learning are epistemologies that cannot easily be related to phenomena, only an indirect operationalization of research questions is possible. Hence, interview and observation guidelines are strongly theory driven and in interviews mainly estimations have been inquired. Research questions have been:

- How do theories in use and local theory show during the performance?

- What are triggers for explicating background assumptions? 


\section{Proceedings of OLKC 2007 - “Learning Fusion”}

- Do local theories and theories in use change through performing the Process Rally?

- What are triggers for change of background assumptions?

- What effect has change of background assumption on work practice?

- Does expansive learning take place in work practice? In what fields with what effects?

- Can expansive learning be related to the Process Rally and the change of background assumptions?

- Does the use of espoused theories increase in operational practice?

Participatory observation took place during 12 performances of the Process Rally. 58 people have been interviewed between three and 12 months after they participated at the rally. Additionally five managers have been interviewed who have not contributed at the rally. Compared to the overall number of people participated in this period of time, approximately $45 \%$ have been reached through interviews (see table 1 ).

\begin{tabular}{|l|c|}
\hline \multicolumn{1}{|c|}{ Function } & Interviewees \\
\hline Administration/Planning & 16 \\
\hline Laboratory & 10 \\
\hline Production & 22 \\
\hline Manager participating & 10 \\
\hline Total participants interviewed & $\mathbf{5 8}$ \\
\hline Manager not participating & 5 \\
\hline Total interviewees & $\mathbf{6 3}$ \\
\hline
\end{tabular}

Table 1: List of Interviewees

\subsection{Outcomes}

\section{Observation results}

Observations show that participants develop a shared understanding about the production process through corporate acting and discussing. The group forming process is characterized through discussions about the different perspectives on work practice. This procedure is essential to provide a mutual understanding about the rally participants. Subsequently theories in use are explicated on the first sight (not clear, at least to me). With ongoing rally practice, not only aspects relevant for the rally are discussed but different understandings of work as a whole are reflected. Hence, to some extent convictions and basic understandings are explicated and discussed. Between participants it is more a collectively shared local theory which can be identified then standardized theories in use. Comparing the development of local theory and theories in use, a significant overlap concerning convictions and basic understandings can be identified, but quite different views in terms of work related theories.

Participants are confronted with different views and opinions about practice. This, however, does not result in contradictions and conflict but rather in a corporate search for solutions. 


\section{Proceedings of OLKC 2007 - “Learning Fusion”}

The range of the newly developed background assumptions goes further than their previous understandings. This aspect results from a discursive process of the whole production chain, which is brought about by people working in different functions and processes. Change of background assumptions through the Process Rally is mainly triggered through being in the original work context. The different views of the participants contribute pieces of a puzzle to a whole picture of work, which is collectively discussed and analyzed. Since this process is independent from operational work and hierarchical constraints, contradictions and double binds do not occur.

Comparing different group compositions, change of background assumptions are likely to occur when different functions and views meet that stand in direct relation to the production process. Homogenous groups and participants that have no direct relation to the production process show far less change in local theory.

Effects of expansive development could obviously not be observed. However, the rally proves to be a forum for reflection and discussion on operational practice. Existing practice is questioned and ideas for new change are brought about. Yet, the ideas often remain superficial, although contradictions occur. In most cases an internal expert of the group provides justifications of the existing procedures that the discussion partners find reasonable. Frequently used explanations are process constraints, complexity of the process or external constraints.

\section{Interview results}

The majority of interviewees stated that they changed their understanding of current work assignments, because of their participation in the rally. This was especially true in regard to aspects such as widening the horizon and awareness of process constraints have been mentioned. Further, interviewees mentioned that compared to colleagues that had not been participating so far, the view of work changed significantly, which often has brought about discussions. Discrepancies occur between non- and participants through a changed focus of work: whilst the first are often oriented to perform their actions are the latter more oriented in producing a product "fit for purpose" since they experienced requirements and purpose of the product. Hence, responsibilities of participants enhanced.

However, discussions between non- and participants that result from different views do hardly lead to contradiction and conflict. Different views are tacitly accepted as long as they do not fundamentally question existing work structures and principles. At the beginning of the Process Rally program, changed assumptions and views have been only shared by participants, who have not necessarily been direct cooperation partners in daily work. Hence the new local theory has been more or less singular. With the ongoing rally performances the number of people sharing different views has grown significantly. Hence the new local theory diffused through the operational work groups until it has become a leading perspective within production. Interviews further showed that despite the different functions participants represent, and despite the different rally performances they took part in, they developed a widely overlapping local theory.

Considering change and development of work processes and communities, the following aspects could be identified. Although nearly all participants mentioned the change of their general understandings and view of work, development of activity can only partially be 


\section{Proceedings of OLKC 2007 - “Learning Fusion”}

identified. It can be distinguished between different types of (expansive) development: Participants use personnel contacts of the rally to bring about new cooperation relations which also change communication paths. New activities are brought about, e.g. mutual information and self-organized training between workers from different work places. This goes along with a new high regard for their own work and the work of others - a typical aspect of changed values. Operational work, however, is changed only in very few cases. People often mention that the rally experience does not go deep enough to get input for change of manufacturing process and that the work constraints are of such complexity that change has not been feasible and desirable.

Comparing statements of workers and non-participating managers the following differences can be identified: workers are themselves hardly aware of the visible effects of the rally in their daily work. Most managers, however, have identified a different atmosphere, different responsibilities and effectiveness - aspects that can clearly be related to change in local theory. They further see an increase of these issues correlating with the rally life cycle - an indication that the changed local theory has diffused the organization. Although the managers interviewed work in various functions, great homogeneity can be identified concerning their estimations of aspects that changed through the process rally.

\section{DISCUSSION}

In his concept of expansive learning, Engeström regards double-bind-situations as prerequisite for development. The double bind can only be solved through a change of background assumptions. Hence, in Engeström's model, change of background assumptions can be seen as a succession of double binds and contradictions $(1987 ; 2001)$. The theoretical and empirical exposition in this paper, however, show that change of background assumptions can also be brought about through corporate reflection. Consequently, expansive development is not necessarily a result of contradictions. Therefore, especially in terms of organizational development, the concept of Engeström can be supplemented in the following aspects:

(1) Background assumptions should be differentiated in a more action-oriented knowledge facet (model: theories in use), and in a more general activity oriented aspect which represents values and convictions (local theory). Both can be described as tacit and collectively shared. However, the local theory reaches much further and provides higher stability than do theories in use. Further, the empirical results show that theories in use are much more related to a specific field or area within the organization. Local theory however shows, depending from the input information, great homogeneity throughout an organization: Although the practice of the Process Rally differs from performance to performance, local theory of participants provide significant overlap, more or less independent from participants' different positions and activities or from the communities to which they contribute. This homogeneity, however, depends on mutual shared experience of the organization members. The Process Rally can be seen as such an experience, which goes far beyond simple knowledge transfer and also further then unreflected practicing. Theories in use, however, include implicit knowledge of actions and processes. Therefore they strongly depend on process related requirements. 


\section{Proceedings of OLKC 2007 - “Learning Fusion”}

(2) The aspect that background assumptions are closely related to manifestations (what Argyris and Schön call "espoused theories" and Baitsch entitles "materialization") shows how the concepts of local theory and theories in use can be related to human cognition. Background assumptions can, on the one hand, reflected and reified. Explicit theories or artefacts result out of this process. On the other hand, practicing leads to an incorporation of framework conditions, such as structures and rules. Through the incorporation new background assumptions are created. In the short run, there are namely theories in use, on the long run develop values and general understandings. In work communities a change of background assumptions is always a more or less explicit procedure, since the mutual understandings have to be discussed before new paths can be chosen. However, focus in such discussions is rather to develop a mutual understanding what drives activity then explicating backgrounds of thinking.

(3) The empirical analysis shows, that corporate reflection can lead to change of background assumptions. However, one should bear in mind a set of prerequisites for such "background changing" types of reflection: Participants should on one hand be close to their normal working context. Hence, they can relate their visual, audible and manual impressions to their personal background. On the other hand, they should be away from constraints of daily work and its power relations. Further, reflection basically emerges out of the process of corporate practicing. Hence, practicing and reflecting should be in close relation. It is finally the cooperating community which is responsible for the quality of reflection. Participants should provide knowledge and experience of the process but also represent various views and opinions. Thus, as empirical results show, a mixed group is essential to enable fruitful and far reaching reflection on operational practice. Otherwise in the case of homogeneous groups, activity is not questioned and actions remain at an intuitive level.

(4) Development takes place not only as a result of contradictions but also as consequence of an enhanced views and understandings of practice. The empirical survey confirms that expansive development takes place without double-binds, but based on enlarged experience and developed background assumptions. However, bearing in mind organizations as unit of analysis, one should distinguish between different types of expansive development:

a. New direct cooperation relations develop that evade inefficient formal relations. These new communities cross boundaries of existing structures.

b. Additional activities are developed that focus specific aspects having hardly been recognized in the organization so far (e.g. a self organized training and information policy).

c. Existing operational activities are changed. This aspect, however, mainly shows in administrative processes.

Type $\mathrm{a}$ and $\mathrm{b}$ can be identified far more frequently then type $\mathrm{c}$. Both $\mathrm{a}$ and $\mathrm{b}$ can be realized without a significant change in the existing organization. It develops in parallel to the existing practice in a gradual noticeable process. Type c considerable affects processes and structures. Hence, it cannot be carried out without confrontation. Therefore, it only occurs in administrative departments where self-organization of work is more disseminated then in manufacturing departments. As a result, it can be concluded that expansive development triggered through enlarged background assumptions avoids conflict. This is achieved through deviations in development such as type a and b. Referring to Engeström, this aspect 


\section{Proceedings of OLKC 2007 - “Learning Fusion”}

can be explained through the fact that participants do not see a necessity to deal with conflicts since no threatening contradictions exist in work processes.

The concept of Engeström provides a clear idea of what can happen to individuals, communities and organizations when background assumptions change: the development of social systems is possible. To provide change not only on a level of close cooperation relations (respectively to avoid failure of expansive learning), success and failure factors of expansive development in organizations should be discussed. The more complex an organization is the higher are the dependencies between communities. Hence, change within one community challenges the surrounding ones and is likely to produce resistance. Development in organizations would become a question of power. This consequence can be avoided through diffusion of changed local theories throughout the organization. Results of the Process Rally show that after a diffusion rate of 20 to 30 percent (Schulz 2006: 229) of organization member having participated at the Process Rally, an internal climate of change and development has been created. In this context, it has shown most important, that mixed groups from different parent communities have participated at the rally. Hence, support for change has come not only out of one community but from cooperation partners all over the organization. The positive effect, based on the comparable low number of maximum $30 \%$, can also be seen in the people participating at the Rally. After a certain warming-up period, several key-persons participated at the rally, which finally enhanced the effect of changed background assumptions. Hence, organizational learning not only depends on changed background assumptions but also on the diffusion of these values and understandings in the organization.

\section{CONCLUSIONS}

Through merging theories of background assumptions with the conceptualization of expansive learning both models could be expanded. Engeström's theory of expansive learning has been specified in terms of what happens if development takes place in organizations. Engeström considers the change of background assumptions as being essential in the cycle of expansive learning. Therefore, especially the local theory of Baitsch delivers a picture what these background assumptions are characterized through how they with focus on the collective aspect develop and change. In contrast, Engeström explains what can happen if local theory changes - expansive development. Further, if considering the cycle of expansive learning closer, it can be clearly distinguished between the two facets of background assumptions: theories in use and local theory. Hence, the merger of the models leads to a further clarification within one of the conceptions.

This merger of the theories is based on a comparable paradigmatic basis. Therefore, there could hardly any contradictions between theories be identified ${ }^{\dagger}$. The paradigmatic basis of 'theories in practice' has finally enabled the merger of the theories. Through the empirical analysis, where both aspects have been considered, background assumptions and expansive development, the theories and its effects on organizational practice could be refined.

\footnotetext{
$\dagger$ In this paper the difference between action and activity playing a central role in Engeströms conceptualizations has not been discussed since Argyris and Schön do not distinguish between these expressions. However the use of the terms action and activity in the text implicitly represents the activity theoretic distinction.
} 
Finally, as main results of the paper, it can be concluded that tacit background assumptions can develop and change through corporate practicing and reflection. Especially a type of practicing which is close to work reality but away from its daily constraints leads to reflection and change. Further, such reflection group should provide knowledge and knowing of the process considered but also represent different views that challenge existing perspectives. However, to avoid this as a singular event experience, it should be ensured that a considerable number of organization members gain the chance to participate in it in such an experience. This diffusion of changed background assumptions should be seen as a prerequisite to enable change and development throughout the organization.

\section{REFERENCES:}

Argyris, C. \& D. Schön (1978) Organizational learning: a theory of action. Reading: Addison-Wesley.

Argyris, C. \& D. Schön (1996) Organizational Learning II: Theory, Method and Practice. Reading: Addison-Wesley.

Baitsch, C. (1993) Was bewegt Organisationen? [What drives organizations?] Frankfurt, Zürich: Campus.

Baitsch, C. (1996) 'Wer lernt denn da? Bemerkungen zum Subjekt des Lernens' [Who is learning there? Comments on the subject of learning]. In H. Geißler (Ed.): Arbeit, Lernen und Organisation. Weinheim: Deutscher Studienverlag, 215-231.

Bateson, G. (1972) Steps to an Ecology of Mind. New York: Ballantine Books.

Bourdieu, P. (1990) The Logic of Practice. Cambridge: Polity Press.

Brown, J. S. \& P. Duguid (1991). 'Organizational learning and communities of practice'. Organizational Science, 2, 40-57.

Brown, J.S. \& P. Duguid (2001) The Social Life of Information. Boston: Harvard Business School Press.

Dewey, J. (1988) Experience and Education. In J.A. Boydston (Eds.), Later Works 13. Carbondale: Southern Illinois University Press. (Original 1938).

Elden, M. (1983) 'Democratization and participative research in developing local theory'. Journal of Occupational Behaviour, 4, 1-8.

Engeström, Y. (1987) Learning by expanding: An activity-theoretical approach to developmental research. Helsinki: Orienta-Konsultit.

Engeström, Y. (2001) 'Expansive learning at work: toward an activity theoretical reconceptualization'. Journal of Education and Work 14/1, 133-156.

Fleck, L. (1935) Entstehung und Entwicklung einer wissenschaftlichen Tatsache. [Emergence and development of a scientific fact]. Basel: Benno Schwabe.

Gergen, K. (1999) An invitation to social construction. London: Sage.

John-Steiner, V. (1984) 'Learning styles among pueblo children'. Quarterly Newsletter of the Laboratory of Comparative Human Cognition 6, 57-62.

Kerosuo H. (2006) Boundaries in action. Helsinki: University Press

Kuhn, T. (1962) The structure of scientific revolution. Chicago: University of Chicago Press.

Nonaka, I. \& H. Takeuchi (1994) The knowledge creating company. Oxford: University Press.

Orr, J. E. (1996) Talking about machines: an ethnography of a modern job. Ithaca, NY: Cornell University Press. 
Rüegg-Stürm, J. (2003) Das neue St. Galler Management-Modell: Grundkategorien einer integrierten Managementlehre: der HSG-Ansatz [The new St. Gall managementmodell - basic cathegories of integrated management learning]. Bern: Haupt.

Scholz, H. (2002) 'Regionale Tätigkeits- und Lernagentur - wichtiger Bestandteil einer progressiven regionalen Lernkultur' [Regional activity and learning agency - an important element in a progressive regional learning culture]. Quem-Bulletin 6/2002, 5-9.

Schulz, K.-P. (2005) 'Learning in complex organizations as practicing and reflecting: a model development and application from a theory of practice perspective'. Journal of Workplace Learning, 17/8, 493-507.

Schulz K.-P. (2006) Die Prozessrallye: Lerntätigkeit in Organisationen - Eine praxistheoretische Modellentwicklung und ihre Anwendung im Unternehmen [The Process Rally: Learning activity in organizations - A practice theoretic conceptualization and its application in industry]. Münster: Waxmann.

Schulz, K.-P. \& J. Aderhold (2004) Reflected Development of Knowing vs. Knowledge Transfer. Proceedings of the $20^{\text {th }}$ EGOS-Colloquium. Ljubljana.

Swan, J., H. Scarbrough \& M. Robertson (2002) 'The construction of 'Communities of Practice' in the management of innovation'. Management Learning 33(4), 477-496.

Vygotsky, L. S. (1978), Mind in society. The development of higher psychological processes. Cambridge: Harvard University Press.

Wenger, E. C. (2003) 'Communities of practice and social learning systems'. In D. Nicolini, S. Gherardi, D. Yanow (Eds.): Knowing in organizations: A practice based approach. Armonk, New York: M.E. Sharpe, 76-99. 